\title{
PARALYSIS OF CONJUGATE VERTICAL OCULAR MOVEMENTS AND DISTURBANCE OF SLEEP RHYTHM*
}

\author{
BY \\ ROBERT C. K. LOH AND K. Y. CHAN \\ Departments of Ophthalmology and Medicine, General Hospital, Singapore
}

THE association of paralysis of conjugate vertical movements of the eyes and disturbance of sleep rhythm has, as far as we are aware, never been reported previously. In view of the recent interest in the ascending reticular activating system which profoundly affects the state of consciousness, it was thought worthwhile to report this case.

\section{Case Report}

A Chinese woman aged 77 years was referred to our hospital in "coma". The history was that she was perfectly well when she took her usual afternoon nap on January 18,1963 , and that her daughter became worried when she failed to wake up from her sleep; she found her snoring, with one arm hanging limply over the edge of the bed; the dentures loose, and slight frothing at the mouth. She was known to have hypertension for over 20 years; 12 years ago she had a transient attack of weakness on the right side, and 6 years ago an episode of "dizziness".

Examination.-On admission to hospital, she could not be roused. The only response was some unintelligible mutterings and flickering movements of the upper eyelids without actual opening of the eyes. The right pupil was pinpoint in size (abnormality noticed in 1956), the left was dilated, and neither reacted to light. There was upper motor neurone paralysis involving the right side of the body. The blood pressure was $200 / 100 \mathrm{~mm}$. Hg. There was generalized thickening and tortuosity of the peripheral blood vessels of the limbs.

She remained in this state for 3 days. On the fourth day, she was conscious but rather confused and there was still some weakness on the right side of the body.

On the fifth day after the onset of this period of "coma", a complete ophthalmological examination was made. At this stage, we were able to have the full co-operation of the patient, and we were able to demonstrate certain abnormalities which were confined to the eyes. The recovery of muscle power was complete and there were no pathological reflexes present.

The visual acuity was $6 / 18$ in each eye unaided, and 6/9 with correction. She was hypermetropic. The horizontal conjugate movements were full, on both dextro- and laevo-version (Figs 1 and 2).

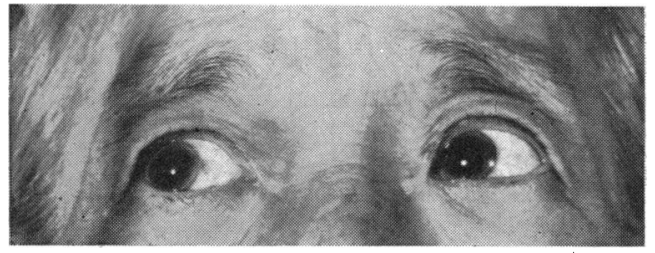

Fig. 1.-Full movement on dextro-version.

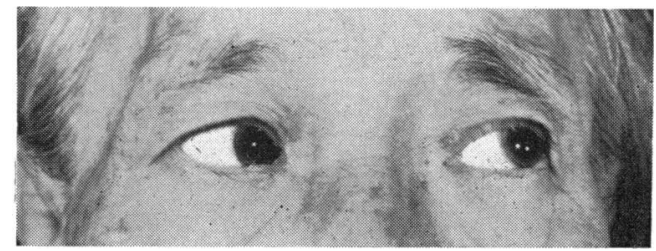

Fig. 2.-Full movement on laevo-version.

- Received for publication July 29, 1963. 
The eyes were completely immobile when the patient was asked to look up and down voluntarily or with fixation on an object moving vertically in front of her (Fig. 3). Flexing and extending the neck produced definite reflex eye movements upwards and downwards, although the range was limited. Bell's phenomenon was exhibited, the eyes turning upwards when the patient closed her eyelids (Fig. 4).

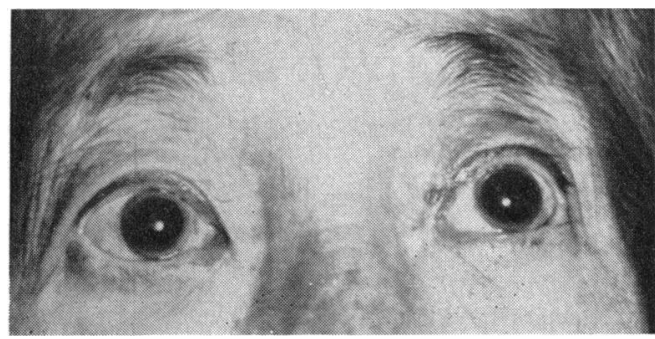

FIG. 3.-The eyes remain in the primary position when movements in the vertical plane are attempted.

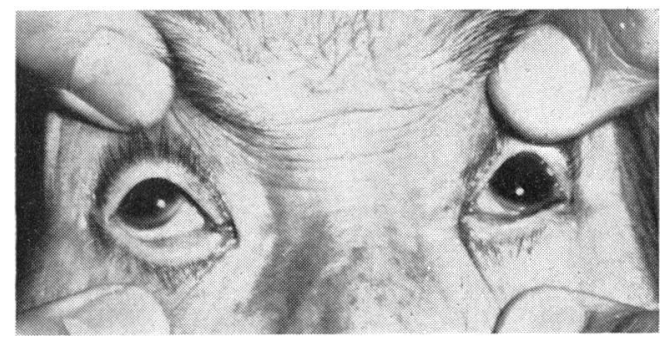

FIG. 4. - The eyes turn upwards when the lids are closed (Bell's phenomenon). Here the lids have been opened by force.

The left pupil was larger $(4 \mathrm{~mm}$.) than the right $(2 \mathrm{~mm}$.) and both reacted sluggishly.

The fundi showed arterio-sclerotic retinopathy with a few superficial haemorrhages and hard exudates. The visual fields were full. The ocular tension was normal in each eye.

The cerebro-spinal fluid was normal and serological tests gave no evidence of syphilis.

During this period, it was noticed that the patient fluctuated between full consciousness and deep sleep from which she could not be roused, but there was no recurrence of hemiplegia. Methylamphetamine injections abolished the tendency to deep sleep during the day, and the patient was subsequently maintained on dextroamphetamine tablets. The tendency to fall asleep during the day recurred on withdrawal of the drug, but the depth of sleep was less and the patient could be roused from it.

\section{Discussion}

The supranuclear mechanism for conjugate vertical movements of the eyes is situated at the level of the superior colliculus in the upper part of the midbrain, the centre for conjugate elevation being situated at a higher level that that for conjugate depression (Brain, 1962a).

Paralysis of vertical movements is much more rare than paralysis of horizontal movements. According to Duke-Elder (1949), such a disturbance does not occur clinically in cortical or subcortical lesions, but shows with considerable exactness a lesion in the subthalamic or upper peduncular region in front of the colliculi. This localized damage may cause a loss of vertical movements, most usually of upward movement, less frequently of both upward and downward, and least frequently of downward movement alone. Occasionally the lid may be retracted or ptosed, and sometimes disturbances of the pupillary reaction are seen.

Brain (1962b) has shown that the ascending reticular activating system, which extends from the lower border of the pons to the centromedial thalamus, profoundly influences the state of consciousness. The lesion in this case was probably situated somewhere in the upper part of the midbrain. It would seem that the reticular activity system lies in close proximity to the supranuclear centres for conjugate vertical movements in the mid brain. The lesion was probably ischaemic in nature, as the result of cerebral atherosclerosis. This is supported by the sudden onset and 
rapid recovery, the previous history of a transient attack of "hemiparesis", and the state of the peripheral blood vessels. The normal cerebrospinal fluid and the age of the patient excluded the possibility of encephalitis, syphilis was excluded by negative serological tests, and the clinical improvement precluded the possibility of neoplasm.

\section{Summary}

A case of paralysis of conjugate vertical movements of the eyes and disturbance of sleep rhythm is presented. The nature and site of the lesion are discussed.

We wish to thank Professor G. A. Ransome for his encouragement and advice and the Director of Medical Services for permission to publish.

\section{REFERENCES}

BraIN, R. (1962a). “Diseases of the Nervous System”, 6th ed., pp. 66-67; 816-817. Oxford University Press, London.

(1962b). "Recent Advances in Neurology and Neuropsychiatry", 7th ed., pp. 3-6; 8-9. Churchill, London.

Duke-Elder, S. (1949). “Text-Book of Ophthalmology”, vol. 4, p. $4163 . \quad$ Kimpton, London. 